\title{
ANALISIS TINGKAT KEPUASAN MAHASISWA TERHADAP KUALITAS JASA (PELAYANAN) AKADEMIK FAKULTAS TARBIYAH DAN KEGURUAN IAIN RADEN INTAN LAMPUNG
}

\author{
Yetri \\ Fakultas Tarbiyah dan Keguruan UIN Raden Intan Lampung \\ yetri.hasan@ radenintan.ac.id
}

\begin{abstract}
Abstrak
Pelayanan pendidikan adalah bagian dari berbagai faktor yang ikut menentukan kesuksesan mahasiswa menyelesaikan serangkaian proses akademik secara tepat waktu di sebuah perguruan tinggi. Berbagai keluhan diungkapkan mahasiswa terkait dengan pelayanan akademik, hal ini menjadi alasan penting dan menarik untuk diteliti. Tujuan penelitian ini adalah untuk menentukan capaian kepuasan mahasiswa terhadap pelayanan jasa akademik pada program studi MPI Fakultas Tarbiyah dan Keguruan IAIN raden Intan Lampung. Kualitas pelayanan dalam penelitian ini diukur rmelalui SERVQUAL dengan lima aspek kulitas, yaitu reliability, responsiveness, assurance, empathy dan tangible. Analisis data menggunakan analisis deskriptif dengan mengukur presentase ketercapaian setiap dimensi kualitas pelayanan. Hasil penelitian menunjukkan, pencapaian pada dimensi tangibles sebesar $65 \%$, pencapaian pada dimensi reliability sebesar $73,75 \%$, pencapaian pada dimensi responsiveness sebesar $63 \%$, pencapaian pada dimensi assurance sebesar $68 \%$, dan pencapaian pada dimensi empathy sebesar $68 \%$. Dengan kata lain, tingkat kepuasan pelanggan/mahasiswa, secara umum baru berada pada kategori sedang/cukup.
\end{abstract}

Kata Kunci: Kualitas Pelayanan, Kepuasan Mahasiswa, Tangibility, Reliability, Responsiveness, Assurance, Empathy. 


\section{PENDAHULUAN}

Perkembangan era globalisasi saat ini mempunyai dampak yang luas pada berbagai aspek, bukan hanya pada sektor ekonomi, social politik, tetapi juga berpengaruh pada sektor pendidikan. Hal ini sejalan dengan semakin berkembangnya kecenderungan ditengah masyarakat bahwa pendidikan menjadi kebutuhan prioritas, bukan hanya sekedar memperoleh ilmu pengetahuan, tetapi juga bentuk investasi untuk masa depan yang lebih baik di era kompetitif ini.

Sejalan dengan itu, telah terjadi perubahan yang fundamental di lingkungan perguruan tinggi. Organisasi perguruan tinggi dituntut untuk mampu memberikan pelayanan berkualitas tinggi, didukung oleh sistem evaluasi yang akuntabel. Oleh karena itu, agar dapat terpenuhi, maka perguruan tinggi perlu membangun kepercayaan masyarakat, dengan mengimplementasikan berbagai program kerja yang relevan, sehingga jaminan kualitas, pengendalian kualitas, serta perbaikan kualitas dapat berjalan secara bersinergi satu dengan yang lainnya. Pengendalian, penjaminan, serta perbaikan kualitas tersebut dapat dialngsungkan pada institusi perguruan tinggi, dengan melakukan evaluasi secara cermat melalui proses akreditasi oleh BAN-PT.

Terkait dengan peningkatan kualitas tersebut, secara spesifik BAN PT juga telah menetapkan aturan bagi setiap perguruan tinggi untuk wajib melakukan survei kepuasan mahasiswa terhadap layanan aktivitas akademik yang diberikan perguruan tinggi bersangkutan. Ketentuan yang dikeluarkan oleh BAN PT di atas, mengisyaratkan betapa pentingnya evaluasi atas kualitas jasa (pelayanan) yang diberikan sebuah perguruan tinggi pada pelanggannya, khususnya mahasiswa. Penyediaan layanan yang berkualitas menjadi salah satu faktor penunjang keberhasilan lembaga perguruan tinggi. Di samping itu, makin disadari bahwa kepuasan mahasiswa sebagai pelanggan pada perguruan tinggi merupakan aspek yang sangat penting untuk dipertahankan agar organisasi perguruan tinggi tetap survive dalam bertahan dan memenangkan persaingan pada saat ini.

Secara utuh kualitas perguruan tinggi tidak terlepas dari kinerja masing-masing fakultas sebagai subunit dari organisasi induknya. Keberhasilan fakultas sebagai unit kerja diperguruan tinggi salah satunya ditentukan oleh sejauh mana kualitas layanan dapat dirasakan oleh mahasiswa sebagai pelanggan.. Dalam kontek ini, pelayanan yang bermutu dapat diidentifikasi melalui kepuasan mahasiswa sebagai pelanggan. Hal ini sejalan dengan apa yang diungkapkan Cravens dalam Handayani dkk, bahwa, untuk dapat mencapai tingkat kepuasan yang tinggi, maka dapat dipastikan pemahaman tentang apa yang diinginkan oleh pelanggan harus benar-benar dapat diketahui dengan baik, serta dengan membangun 
komitmen setiap orang yang ada dalam sebuah organisasi untuk memenuhi kebutuhan pelanggan.1

Fakultas Tarbiyah dan Keguruan (FTK), merupakan salah satu fakultas terbesar yang ada di IAIN Raden Intan Lampung dengan memiliki 10 program studi unggulan, yaitu Prodi: PAI, MPI, Bahasa Arab, Bahasa Inggris, BKI, Biologi, Fisika, Matematika, PGRA, dan PGMI. Secara kuantitas Fakultas Tarbiyah memiliki jumlah mahasiswa yang sangat besar, yaitu mencapai 7760 orang, bahkan menempati urutan pertama penyumbang jumlah mahasiswa terbanyak di IAIN Raden Intan.

Khusus dalam penelitian ini peneliti membatasi hanya pada prodi MPI, mengingat dua tahun terakhir Prodi MPI memperoleh perhatian yang makin besar dari masyarakat terbutki dengan meningkatnya peminat yang mendaftar pada prodi MPI ini, yaitu naik lebih dari 100\% (data tahun 2015), pada saat ini jumlah seluruh mahasiswa MPI berjumlah: 342 orang mahasiswa (Sumber: Data Umum IAIN Raden Intan tahun 2014). Namun demikian, peningkatan jumlah mahasiswa di Fakultas Tarbiyah belum sepenuhnya dapat dibarengi dengan peningkatan pelayanan jasa akademik berkualitas bagi mahasiswa. Masih banyak bermunculan keluhan-keluhan mahasiswa sebagai pelanggan utama terkait dengan kualitas pelayanan akademik yang mereka dapatkan. Keluhan-keluhan tersebut dapat diklasisfikasi sebagaimana diilustrasikan dalam tabel 1 berikut:

Tabel. 1. Tabel Klasifikasi Keluhan Pelanggan (Mahasiswa) MPI Fakultas Tarbiyah

\begin{tabular}{|c|l|l|}
\hline NO & \multicolumn{1}{|c|}{ DIMENSI PELAYANAN } & \multicolumn{1}{c|}{ ASPEK KELUHAN } \\
\hline 1 & $\begin{array}{l}\text { Keandalan (Reliability): merupakan hal yang } \\
\text { berkaitan dengan kesediaan dan kemampuan } \\
\text { untuk memberikan jasa secara akurat, dapat } \\
\text { dipercaya dan dapat diandalkan }\end{array}$ & $\begin{array}{l}\text { Jadwal dan pelaksanaan kuliah } \\
\text { Kurikulum dan silabus mata kuliah } \\
\text { Penilaian dalam perkuliahan }\end{array}$ \\
\hline 2 & $\begin{array}{l}\text { Cepat Tanggap (Responsiveness): berkaitan } \\
\text { dengan kemauan atau kesiapan dalam membantu } \\
\text { pelanggan dengan menyediakan pelayanan } \\
\text { secara cepat sesuai yang dibutuhkan pelanggan. }\end{array}$ & $\begin{array}{l}\text { Pemberina pelayanan secara cepat, } \\
\text { Respon karyawan Daya tanggap } \\
\text { karyawan Kesabaran karyawan } \\
\text { Kenyamanan dalam pelayanan }\end{array}$ \\
\hline 3 & $\begin{array}{l}\text { Jaminan (Assurance); berkaitan dengan } \\
\text { kemampuan karyawan untuk melayani } \\
\text { kebutuhan pelanggan secara memadai } \\
\text { (pengetahuan, kesopanan, dan dapat dipercaya) }\end{array}$ & $\begin{array}{l}\text { Kemudahan melakukan registrasi } \\
\text { Kesediaan mendegar, menanggapi } \\
\text { pendapat, sasaran dan keluhan } \\
\text { mahasiswa Profesionalisme staf }\end{array}$ \\
\hline 4 & $\begin{array}{l}\text { Empati (Emphaty): berkaitan dengan } \\
\text { kepedulian untuk memberikan perhatian secara } \\
\text { individual kepada mahasiswa, kemudahan }\end{array}$ & $\begin{array}{l}\text { Kemudahan mengurus adminsitrasi } \\
\text { kuliah (transkrip Nilai, KRS, dsb) } \\
\text { Kesediaan mendegar, menanggapi }\end{array}$ \\
\hline
\end{tabular}

1 Handayani, R, Yermias T. K., dan Ratminto. 2003. "Analisis Kepuasan Pemakai terhadap Pelayanan Perpustakaan Nasional Provinsi Daerah Istimewa Yogyakarta”. (Yogjakarta, Sosiosains, Volume 17 Nomor 2, April 2003). Pasca Sarjana Fisipol UGM, page 39. 


\begin{tabular}{|c|l|l|}
\hline & $\begin{array}{l}\text { untuk dihubungi, dan memahami kebutuhan } \\
\text { mahasiswa. }\end{array}$ & pendapat, saran,keluhan mahasiswa \\
\hline 5 & $\begin{array}{l}\text { Bukti Nyata (Tangibles);merupakan hal yang } \\
\text { berkaiatan dengan fasilitas berwujud fisik, } \\
\text { peralatan dan alat komunikasi yang dimiliki oleh } \\
\text { perguruan tinggi (fakultas). }\end{array}$ & $\begin{array}{l}\text { Sarana komunikasi , kemudahan } \\
\text { akses, perpustakaan, Area parkir,, } \\
\text { peralatan dan media pembelajaran, } \\
\text { laboratorium ketersediaan air bersih }\end{array}$ \\
\hline
\end{tabular}

Sumber Primer: (Hasil Wawancara)

Sejalan dengan uraian diatas, terdapat berbagai atribut kualitas jasa pelayanan yang ikut menentukan tingkat kepuasan mahasiswa, dalam konteks ini adalah sebagaimana telah dikemukakan oleh Valarie dkk, yaitu mencakup dimensi; reliability, responsiveness, assurance, emphaty, dan tangibles2. Oleh karena itu diperlukan suatu analisis yang mendalam dan kajian yang komprehensif tentang sejauh mana kepuasan mahasiswa terhadap dimensidimensi kualitas dalam pelayanan akademik di Fakultas Tarbiyah dan keguruan sebagaimana diuraikan di atas. Berdasarkan paparan yang telah diuraian pada di atas, maka pertanyaan penelitian diajukan sebagai berikut: Bagaimanakah kepuasan mahasiswa program studi MPI Fakultas Tarbiyah IAIN Raden Intan Lampung terhadap dimensi-dimensi kualitas pelayanan akademik?

\section{METODE PENELITIAN}

Jenis penelitian ini adalah penelitian lapangan dengan metode kualitatif deskriptif. Pengambilan sampel dilakukan dengan teknik proportionale stratified random sampling. Secara teknis, penetapan jumlah sampel dengan berpedoman pada tabel yang dikembangkan dari Isaac dan Michael, sehingga dapat ditetapkan jumlah sampel sebanyak 30 orang dari jumlah populasi sebesar 342 orang. Pengumpualan data menggunakan daftar inventori/angket, dan pedoman wawancara serta observasi. Instrumen digunakan untuk menjaring data dimensi kualitas pelayanan akademi, meliputi: dimensi tangible, reliability, responsinveness, assurance maupun empaty. Skala pengukuran menggunakan skala Likert. Skala ini berhubungan dengan pernyataan tentang pendapat, persepsi dan sikap responden terhadap pelayanan akademik. Data yang diperoleh dari variabel yang diukur, ditabulasi dan dinyatakan dalam persentase, sekaligus sebagai kriteria nilai pencapaiannya:

2 Parasuraman, Valarie A. Zeithaml, and Leonard L. Berry. 1988. "SERVQUAL: A Multiple - Item Scale for Measuring Consumer Perceptions of Service Quality". Journal of Retailing. Vol 64 (1), page 17 


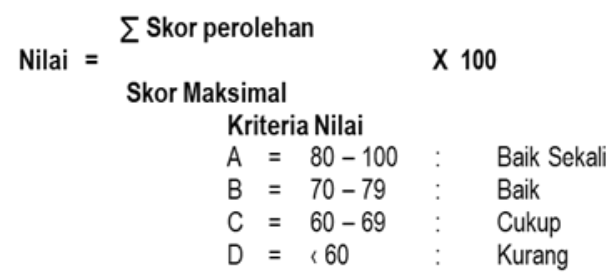

Teknik analisis data menggunakan teknik analisis deskriptif, khususnya analisis pada aspek karakteristik responden penelitian. Selanjutnya untuk mengukur tingkat kepuasan mahasiswa menggunakan analisis kuantitatif deskriptif, yaitu dengan menentukan persentase pencapaian pada tiap dimensi kualitas pelayanan akademik.

\section{PEMBAHASAN}

Pengumpulan dan analisis data diawali dengan mendistribusikan lebih dari 30 buah kuesioner pada rseponden penelitian. Hal ini dilakukan sebagai bentuk antisipasi terhadap kemungkinan kuesioner yang direspon tidak seluruhnya dapat diisi atau dikembalikan. Selanjutnya analisis data penelitian dimulai dari penjelasan mengenai identitas responden, yaitu untuk memberikan gambaran tentang profil responden mencakup aspek jenis kelamin, umur, semester, dan sumber biaya pendidikan. Berikut ini akan disajikan data tentang kondisi atau profil responden berdasarkan masingmasing aspek yang diteliti.

\section{Karakteristik Responden Menurut Jenis Kelamin}

Tabel 2. Karakteristik Responden Berdasarkan Jenis Kelamin

\begin{tabular}{|c|l|c|c|}
\hline NO & JENIS KELAMIN & JUMLAH & PERSENTASE \\
\hline 1 & Laki-laki & 10 & $33 \%$ \\
\hline 2 & Perempuan & 20 & $67 \%$ \\
\hline 3 & Total & 30 & $100 \%$ \\
\hline
\end{tabular}

Sumber: Data Primer yang diolah, 2015

Dari tabel 2. di atas, dapat dijelaskan bahwa komposisi responden terdiri dari jenis kelamin perempuan dan laki-laki. Responden laki-laki berjumlah 10 orang atau sebanyak 33\%, sedangkan responden perempuan sebanyak 20 orang atau sebanyak $67 \%$. Berdasarkan data pada table 2 di atas, dapat disimpulkan bahwa responden berjenis kelamin laki-laki lebih sedikit dari pada responden berjenis kelamin perempuan. 


\section{Karakteristik Responden Menurut Semester}

Tabel 3. Karakteristik responden berdasarkan semester

\begin{tabular}{|c|c|c|c|}
\hline NO & SEMESTER & JUMLAH & PERSENTASE \\
\hline 1 & II & 12 & 40 \\
\hline 2 & IV & 6 & 20 \\
\hline 3 & VI & 9 & 30 \\
\hline 4 & VIII & 3 & 10 \\
\hline & Total & 30 & 100 \\
\hline
\end{tabular}

Sumber: Data Primer yang diolah, 2015

Berdasarkan data pada tabel 3 di atas, dapat dijelaskan bahwa responden pada semester II (dua) berjumlah sebanyak 12 orang (40\%), responden pada semester IV (empat) berjumlah 6 orang (20\%), responden pada semester VI (enam) berjumlah 9 orang (30\%), dan responden semester VIII (delapan) berjumlah 3 orang (10\%). Berdasarkan table data diatas, dapat disimpulkan bahwa responden paling banyak adalah responden yang berasal dari mahasiswa semester II (dua) yaitu berjumlah 12 orang (40\%).

\section{Karakteristik Responden Menurut Sumber Biaya Pendidikan}

\section{Tabel. 4. Karakteristik Responden Berdasarkan Sumber Biaya} Pendidikan

\begin{tabular}{|c|l|c|c|}
\hline No & Sumber Biaya & Jumlah & Persentase \\
\hline 1 & Orang tua & 23 & 77 \\
\hline 2 & Sendiri & 2 & 7 \\
\hline 3 & Famili & 5 & 16 \\
\hline & Total & 30 & 100 \\
\hline
\end{tabular}

Sumber: Data Primer yang diolah, 2015

Berdasarkan data pada table 4 di atas, dapat dielaskan bahwa responden yang pembiayaan pendidikannya bersumber dari orang tua mencapai 23 orang (77\%). Responden yang sumber biaya pendidikannya berasal dari famili/keluarga 5 orang (16\%). Disisi lain jumlah yang terkecil adalah responden yang sumber biaya pendidikan diperoleh dari usahanya sendiri yaitu sebanyak 2 orang (7\%). Yang dimaksud sumber pembiayaan pendidikan mahasiswa dalam konteks penelitian ini adalah sumber keuangan yang dimanfaatkan mahasiswa guna memenuhi kebutuhannya selama mengikuti masa studi.

Analisis selanjutnya, berkaitan dengan tingkat kepuasan mahasiswa program studi Manajemen Pendidikan Islam (MPI), terhadap dimensi kualitas pelayanan akademik. Adapun hasil analisisnya dapat diuraikan sebagai berikut: 


\section{Indeks Kepuasan Mahasiswa Terhadap Dimensi Bukti Fisik (Tangible)}

Merupakan bentuk fisik yag bisa dirasakan dan diamati melalui indra penglihatan, seperti sarana gedung dan front office, kenyamanan ruangan, kerapihan, kebersihan, kelengkapan peralatan komunikasi, dan penampilan karyawan. Pada dimensi kualitas pelayanan yang pertama ini, mengukur fasilitas fisik perguruan tinggi dilakukan melalui pemberian pelayanan kepada mahaiswa. Mengingat pelayanan tidak bisa dilihat, dicium, dan diraba, maka aspek pada bukti fisik ini menjadi sangat urgen sebagai salah satu indikator pengukuran terhadap pelayanan. Dalam kontek ini, mahasiswa menggunakan indera rasa dan penglihatannya untuk menilai suatu kualitas pelayanan pada dimensi fisik mencakup 3 indikator utama, yaitu:

1) Kebersihan, kerapihan dan kenyamanan lingkungan kampus

2) Ketersediaan fasilitas yang memadai (ruang kuliah, praktikum, mushollah, taman, tempat parkir, tempat olah raga, air bersih)

3) Ketersediaan prasarana perkuliahan, seperti computer, laptop, LCD, papan tulis, komputer, jenset yang memadai.

Berdasarkan hasil penelitian kepada 30 orang responden, dapat dideskripsikan tingkat kepuasan mahasiswa terhadap kualitas pelayanan akademik pada dimensi tangible (bukti/wujud fisik), sebagaimana dirinci dalam tabel 5 berikut:

\section{Tabel 5. Tingkat Pencapaian Kepuasan Mahasiswa Tehadap Dimensi} Bukti Fisik

\begin{tabular}{|c|l|c|}
\hline No & \multicolumn{1}{|c|}{ Atribut/Indikator } & $\begin{array}{c}\text { Rata-Rata } \\
\text { Pencapaian (\%) }\end{array}$ \\
\hline 1 & Kebersihan, kerapihan dan kenyamanan lingkungan kampus & 70 \\
\hline 2 & $\begin{array}{l}\text { Ketersediaan fasilitas yang memadai (ruang kuliah, praktikum, } \\
\text { mushollah, taman, tempat parkir, tempat olah raga, air bersih) }\end{array}$ & 60 \\
\hline 3 & $\begin{array}{l}\text { Ketersediaan prasarana perkuliahan (papan tulis, computer, } \\
\text { LCD, laptop, jenset) memadai }\end{array}$ & 65 \\
\hline & Rata-Rata Total & 65 \\
\hline
\end{tabular}

Sumber: Data Primer yang diolah, 2015

Dari hasil data penelitian di atas, menujukkan bahwa bukti fisik (tangible) yang tersedia pada perguruan tinggi memperoleh tanggapan yang beragam dari mahasiswa, namun secara umum tingkat kepuasan mahasiswa terhadap ketersediaan bukti fisik berupa kondisi peralatan, gedung, taman, area parkir, air bersih dan ketersediaan peralatan fisik lainnya berada pada kategori sedang/cukup, yaitu baru mencapai $65 \%$. 


\section{Indeks Kepuasan Mahasiswa Terhadap Dimensi Keandalan (Reliability)}

Dimensi keandalan, merupakan kesediaan dan kemampuan dalam memberikan pelayanan sesuai dengan yang dijanjikan seperti, penyediaan pelayanan sesuai yang dijanjikan, informasi yang lengkap dan akurat yang dibutuhkan mahasiswa, penanganan masalah yang dihadapi mahasiswa, dan penyediaan pelayanan secara tepat waktu. Terdapat 2 komponen yang dikaji dalam dimensi ini, pertama adalah kemampuan organisasi perguruan tinggi untuk memberikan pelayanan seperti yang dijanjikan. Kedua berkaitan dengan seberapa jauh suatu organisasi perguruan tinggi mampu menyediakan layanan yang tepat dan akurat. Dalam kontek penelitian ini dimensi keandalan (Reliability) diukur melalui 4 indikator utama, yaitu:

1) Kecepatan dalam memberikan pelayanan

2) Prosedur pelayanan yang tidak berbelit-belit

3) Ketetpatan informasi terkait dengan nilai, IP dan

4) Kedisiplinan staf dalam kehadiran dan ketepatan waktu bekerja

Berdasarkan hasil penelitian kepada 30 orang responden, dapat dideskripsikan tingkat kepuasan mahasiswa terhadap kualitas pelayanan akademik pada dimensi keandalan, sebagaimana disajikan dalam tabel 6 berikut:

\section{Tabel 6. Tingkat Pencapaian Kepuasan Mahasiswa Tehadap Dimensi} Keandalan

\begin{tabular}{|c|l|c|}
\hline No & \multicolumn{1}{|c|}{ Atribut/Indikator } & $\begin{array}{c}\text { Rata-Rata } \\
\text { Pencapaian (\%) }\end{array}$ \\
\hline 1 & Kecepatan dalam memberikan pelayanan & 67 \\
\hline 2 & Prosedur pelayanan yang tidak berbelit-belit & 70 \\
\hline 3 & Ketepatan informasi terkiat dengan nilai, IP dan IPK & 75 \\
\hline 4 & Kedisiplinan staf dalam kehadiran dan ketepatan waktu bekerja & 83 \\
\hline & Rata-rata Total & 73,75 \\
\hline
\end{tabular}

Sumber: Data Primer yang diolah, 2015

Dari hasil data penelitian di atas, menujukkan bahwa keandalan pelayanan yang diberikan perguruan tinggi memperoleh tanggapan yang beragam dari mahasiswa, namun secara umum tingkat kepuasan mahasiswa terhadap keandalan dalam memberikan pelayanan yang cepat, tidak berbelit-belit, keakuratan informasi yang diberikan, serta kedisiplinan staf dalam kehadiran memberikan pelayanan, berada pada kategori baik, yaitu mencapai $73,75 \%$.

\section{Indeks Kepuasan Mahasiswa Terhadap Dimensi Daya Tanggap (Responsiveness)}

Pada dimensi daya tanggap, berkaitan dengan kemampuan respon karyawan dalam memeberikan tanggapan dan bantuan kepada mahasiswa, serta memberi pelayanan yang cepat dan tanggap. Dimensi daya tanggap ini juga 
meliputi kesigapan karyawan dalam melayani mahasiswa, kerja tim yang solid, kecekatan karyawan dalam menangani transaksi dan penanganan keluhan mahasiswa, kecepatan menanggapi permasalahan-permasalahan akademik yang dihadapi mahasiswa, member informasi yang akurat pada saat memberikan pelayanan, dan komitmen untuk membantu mahasiswa. Dalam konteks ini, mahaiswa sebagai pengguna jasa tidak akan puas apabila waktu yang mereka habiskan untuk menyelesaikan masalah yang merka hadapi terbuang percuma hanya karena karyawan lamban dalam menanganinya.

Dalam kontek penelitian ini dimensi daya tanggap (Responsiveness) diukur melalui 4 indikator utama, yaitu:

1) Responsif terhadap keluhan mahaiswa

2) Kesiapan karyawan membantu mahasiswa

3) Kesigapan dan tanggap dalam mengatasi keluhan pelanggan

4) Mudah ditemui/dihubungi bila ingin berkonsultasi

Berdasarkan hasil penelitian kepada 30 orang responden, dapat dideskripsikan tingkat kepuasan pelanggan (mahasiswa) terhadap kualitas pelayanan akademik pada dimensi daya tanggap, berdasarkan indikator sebagaimana diuraikan di atas, sebagaimana disajikan dalam tabel 7 berikut:

\section{Tabel 7. Tingkat Pencapaian Kepuasan Mahasiswa Tehadap Dimensi} Daya Tanggap

\begin{tabular}{|c|l|c|}
\hline No & \multicolumn{1}{|c|}{ Atribut/Indikator } & \multicolumn{1}{|c|}{$\begin{array}{c}\text { Rata-Rata } \\
\text { Pencapaian (\%) }\end{array}$} \\
\hline 1 & Tanggap terhadap keluhan mahasiswa & 52 \\
\hline 2 & Kesediaan karyawan membantu mahasiswa & 70 \\
\hline 3 & Kecepatan dan tanggap dalam mengatasi keluhan pelanggan & 65 \\
\hline 4 & Mudah ditemui/dihubungi bila ingin berkonsultasi & 65 \\
\hline & Rata-rata Total & 63 \\
\hline
\end{tabular}

Sumber: Data Primer yang diolah, 2015

Dari hasil data penelitian di atas, menujukkan bahwa daya tanggap dalam memberikan pelayanan memperoleh tanggapan yang beragam dari mahasiswa, namun secara umum tingkat kepuasan mahasiswa terhadap daya tanggap dalam mendengarkan keluhan mahasiswa, kesediaan membantu mahasiswa, ketepatan bantuan yang diberikan pada mahasiswa, serta kemudahan staf ditemui mahasiswa berada pada kategori cukup, yaitu baru mencapai $63 \%$.

\section{Indeks Kepuasan Mahasiswa Terhadap Dimensi Jaminan (Assurance)}

Dimensi jaminan, merupakan kemampuan karyawan atas pengetahuan terhadap jasa akademik yang harus diberikan secara tepat kepada mahasiswa, keadilan dalam memberi pelayanan, keramah-tamahan, kesopanan kesopanan dalam memberikan pelayanan, ketepatan dan 
ketrampilan dalam menyampaikan informasi, kesediaan dan kemampuan karyawan memberikan rasa aman. Dimensi jaminan ini juga yang berkaitan dengan kemampuan karyawan dalam menanamkan rasa percaya dan keyakinan kepada mahasiswa. Beberapa aspek dari dimensi ini diantaranya adalah kompetensi dan kredibilitas. Dalam kontek penelitian ini dimensi jaminan (Assurance) diukur melalui 3 indikator utama, yaitu:

1) Keramahan dan perhatian dalam melayani mahasiswa

2) Kecakapan, pengetahuan dan pemahaman yang luas

3) Keamanan mahasiswa terjamin

Berdasarkan hasil penelitian kepada 30 orang responden, dapat dideskripsikan tingkat kepuasan mahasiswa terhadap kualitas pelayanan akademik pada dimensi jaminan, sebagaimana disajikan dalam tabel 8 berikut:

Tabel 8. Tingkat Pencapaian Kepuasan Mahasiswa Tehadap Dimensi Jaminan

\begin{tabular}{|c|l|c|}
\hline NO & \multicolumn{1}{|c|}{ ATRIBUT/INDIKATOR } & $\begin{array}{c}\text { RATA-RATA } \\
\text { PENCAPAIAN (\%) }\end{array}$ \\
\hline 1 & Keramahan dan perhatian dalam melayani /mahasiswa & 74 \\
\hline 2 & Pengetahuan dan kecakapan yang luas & 71 \\
\hline 3 & Keamanan pelanggan/mahasiswa & 81 \\
\hline & Rata-rata Total & 75,3 \\
\hline
\end{tabular}

Sumber: Data Primer yang diolah, 2015

Dari hasil data penelitian di atas, menujukkan bahwa dimensi jaminan dalam meberikan pelayanan memperoleh tanggapan yang beragam dari mahasiswa, namun secara umum tingkat kepuasan mahasiswa terhadap dimensi jaminan pelayanan berupa keramahan dan perhatian dalam meberikan pelayanan, tigkat pengetahuan dan kecakapan dalam meberikan layanan, serta kemanan mahasiswa dalam mendapat jasa pelayanan berada pada kategori baik, yaitu mencapai $75,3 \%$.

\section{Indeks Kepuasan Mahasiswa Terhadap Dimensi Empati (Empaty)}

Dimensi empati, merupakan kemampuan memberikan perhatian kepada mahasiswa, kemudahan untuk menghubungi berbagai pihak berkepentingan di dalam organisasi, kemampuan karyawan untuk berkomunikasi dengan mahasiswa, dan usaha organisasi untuk merespon keinginan dan kebutuhan mahasiswa. Dalam kontek penelitian ini dimensi empati (Empaty) diukur melalui 3 indikator utama, yaitu:

1) Memahami keinginan mahasiswa atau tamu

2) Kemampuan berkomunikasi dengan baik

3) Ketersediaan untuk melayani dan menerima keluhan 
Berdasarkan hasil penelitian kepada 30 orang responden, dapat dideskripsikan tingkat kepuasan mahasiswa terhadap kualitas pelayanan akademik pada dimensi empati, sebagaimana disajikan dalam tabel 9 berikut:

Tabel 9. Tingkat Pencapaian Kepuasan Mahasiswa tehadap Dimensi Empati

\begin{tabular}{|l|l|c|}
\hline NO & \multicolumn{1}{|c|}{ ATRIBUT/INDIKATOR } & $\begin{array}{c}\text { RATA-RATA } \\
\text { PENCAPAIAN (\%) }\end{array}$ \\
\hline 1 & Memahami keinginan mahasiswa & 63 \\
\hline 2 & Mampu berkomunikasi dengan baik & 70 \\
\hline 3 & Kesediaan untuk melayani dan menerima keluhan & 70 \\
\hline & Rata-rata Total & 68 \\
\hline
\end{tabular}

Sumber: Data Primer yang diolah, 2015

Dari hasil data penelitian di atas, menujukkan bahwa dimensi empati dalam meberikan pelayanan memperoleh tanggapan yang beragam dari pelanggan/mahasiswa, namun secara umum tingkat kepuasan pelanggan/mahasiswa terhadap dimensi empati dalam pelayanan berupa kemampuan memahami pelanggan/mahasiswa, berkomunikasi dengan baik, kesediaan menerima keluhan berada pada kategori cukup, yaitu baru mencapai $68 \%$.

Berdasarkan penilaian terhadap indikator pada masing-masing dimensi kualitas pelayanan yang telah ditemukan di atas, dapat kesimpulan bahwa tingkat kepuasan mahasiswa baik terhadap dimensi bukti fisik, dimensi keandalan, dimensi daya tanggap, dimensi jaminan, serta dimensi empaty, secara umum baru berada pada kategori sedang/cukup. Secara komprehensif dapat disajikan pada tabel 10 berikut ini:

\section{Tabel 10. Rangkuman Pencapaian Dimensi Kualitas Pelayanan}

\begin{tabular}{|c|l|c|}
\hline NO & \multicolumn{1}{|c|}{ DIMENSI } & RATA-RATA (\%) \\
\hline 1 & Tangible & 65 \\
\hline 2 & Reliablity & 73,75 \\
\hline 3 & Responsiveness & 63 \\
\hline 4 & Assurance & 75,3 \\
\hline 5 & Empathy & 68 \\
\hline & Rata-rata Total & 69,01 \\
\hline
\end{tabular}




\section{PENUTUP}

Berdasarkan hasil analisis data penelitian, ditemukan secara umum tingkat kepuasan mahasiswa program studi MPI FTK IAIN Raden Intan terhadap kualitas jasa pelayanan akademik, berada pada kategori cukup/sedang, yaitu baru mencapai $69,01 \%$ Dengan demikian ditegaskan bahwa kualitas pelayanan merupakan salah satu faktor penting dalam menenntukan kelancaran proses akademik mahasiswa, dan pada akhirnya dapat mempengaruhi tingkat keberhasilan mahasiswa dalam menyelesaikan studinya. Oleh karena itu perlu dilakukan perbaikan pada setiap dimensi kualitas jasa (pelayanan), khususnya pada dimensi tangible, responsinveness, dan empaty yang masih berada pada kategori cukup/sedang. Dan yang tidak kalah pentingnya adalah perlu dibangun komitmen bersama, baik pimpinan, dosen maupun staf untuk terus menerus meningkatakn pelayanan akademik kepada mahasiswa sehingga proses akademik dapat berjalan lebih kondusif.

\section{DAFTAR PUSTAKA}

Fandy Tjiptono, dan Gregorius Chandra, 2005. Service Quality Satisfaction. Yogjakarta, Penerbit Andi , 2002. Measuring Customer Satisfaction (cetakan ketiga). Jakarta: PT.Gramedia Pustaka Utama.

Freeman, D.K. dan Dart, J. 1993, 'Measuring the Perceived Quality of Professional Business Services', Journal of Professional Services Marketing, Vol.9, No.1.

Gasperz, V. 2002. Mambangun Tujuh Kebiasaan Kualitas dalam Praktek Bisnis Global. PT Gramedia Pustaka Utama, Jakarta.

Handayani, R, Yermias T. K., dan Ratminto. 2003. "Analisis Kepuasan Pemakai terhadap Pelayanan Perpustakaan Nasional Provinsi Daerah Istimewa Yogyakarta”. Sosiosains, Volume 17 Nomor 2, April 2003. Pasca Sarjana Fisipol UGM. Yogyakarta.

Irawan Handi, 2002, 10 Prinsip Kepuasan Pelanggan, PT. Elex Media Komputindo, Jakarta.

J. Supranto, 2002. Metode Penelitian Sosial, PT. Remaja Rosdakarya, Bandung.

Kettinger, J.W. dan Lee, C.C. 1994, 'Perceived Service Quality and User Satisfaction with the Information Services Function', Decision Science, Vol. 23, No. 5/6:737-766. 
Kurniawan, K. 2005. Membangun Kultur Akademik Perguruan Tinggi. http://www.waspada-online.com/ [15-04-20013]

Maria, R. U. 2007. Analisis Tingkat Kepuasan Pelanggan Terhadap Mutu Layanan Jasa Lembaga Pendidikan Musik Farabi Bogor. Skripsi pada Departemen Manajemen, Fakultas Ekonomi dan Manajemen, Institut Pertanian Bogor.

Nasution, M. N. 2004. Manajemen Mutu Terpadu. Edisi Revisi. Ghalia Indonesia, Bogor.

Pannen, P. 2001. Mengajar di Perguruan Tinggi: Pendidikan Sebagai Sistem. Universitas Terbuka, Jakarta.

Parasuraman, Valarie A. Zeithaml, and Leonard L. Berry. 1988. "SERVQUAL: A Multiple - Item Scale for Measuring Consumer Perceptions of Service Quality". Journal of Retailing . Vol 64 (1) pp 12-37

Subiyakto, H.H. 1999, 'Ukuran Kualitas Jasa: Gap Antara Kinerja dan Harapan atau Kinerja?',Wahana, Vol.2, No.1.

Sugiono. 2004. Memahami Penelitian Kualitatif. Alfabeta, Bandung.

Tjiptono Fandy, 1997. Prinsip-prinsip Total Quality Service, Andi Yogyakarta.

Valarie A. Zeithaml, 1990. A. Parasuraman and Leonard L. Berry, Delivering Quality Service, The Free Press, New York.

Vincent Gaspersz, 2002. Manajemen Kualitas dalam Industri Jasa, Gramedia Pustaka Utama, Jakarta.

Zeithaml, A.V., Berry L.L., dan Parasuraman, A. (1993), 'The Nature and Determinants of Customer Expectations of Services', Journal of Academy Marketing Science, Vol. 21. No.1: 1-12. 